
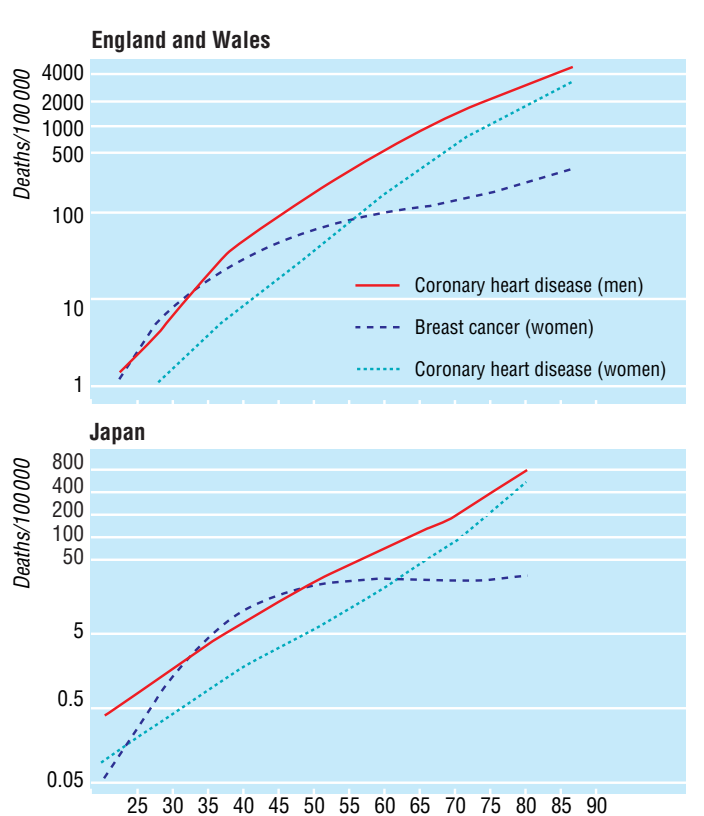

Age (years)

Age specific trends in mortality from coronary heart disease in men and women and from breast cancer in women. Aggregated data for England and Wales (top) and Japan (bottom)

eral environmental risk factors, and if the effect of oestrogen on risk of coronary heart disease is small relative to other risk factors then any effect of the menopause may be masked.

Witteman et al argue that age related trends in coronary heart disease mortality are not inconsistent with an effect of the menopause. ${ }^{4}$ They used simulation models based on levels of risk of coronary heart disease in men to estimate age related trends in "women who never experience a menopause." Such analyses are unrealistic and unhelpful.

Work on the aetiology of coronary heart disease in women has been dominated by the idea that oestrogen plays an important part and is responsible for the sex difference at younger ages. The implications of this are that higher rates of coronary heart disease in men are seen as inevitable and that postmenopausal hormone replacement therapy has become the mainstay of coronary heart disease prevention in women. We conclude that environmental factors are the most important determinants of coronary heart disease in women and men and of the difference in coronary heart disease rates between women and men. ${ }^{5}$

Contributors: All authors conceived the idea for the study. DAL undertook the analysis and wrote the first draft of the paper. All authors contributed to the final report. DAL will act as guarantor.

Funding: DAL is an MRC research training fellow and is funded by the Medical Research Council. Views expressed are those of the authors.

Competing interests: None declared.

Tunstall-Pedoe H. Myth and paradox of coronary risk and the menopause. Lancet 1998;351:1425-7.

2 Tracy RE. Sex difference in coronary disease: two opposing views. J Chronic Dis 1966;19:1245-51.

3 Meilahn E. Sex steroid hormonal influences on coronary artery disease. In: Ness RB, Kuller LH, eds. Health and disease among women. Oxford: Oxford University Press, 1999:155-82.

4 Witteman JCM, Moerman CJ, Westendorp ICD. Myth of the menopause paradox. Lancet 1998;352:407.

5 Lawlor DA, Ebrahim S, Davey Smith G. Sex matters: secular and geographical trends in sex differences in coronary heart disease mortality. BMJ 2001;323:541-5.

(Accepted 12 February 2002)

\title{
Mortality from liver disease in the West Midlands, 1993-2000: observational study
}

\author{
N C Fisher, J Hanson, A Phillips, J N Rao, E T Swarbrick
}

Department of Gastroenterology, Dudley Group of Hospitals NHS Trust, Russells Hal Hospital, Dudley, West Midlands DY1 2HQ

N C Fisher consultant physician and gastroenterologist

Dudley Health Authority, Dudley DY12 2DD

J Hanson public health information specialist continued over
Advanced liver failure carries a poor prognosis, and its prevalence may be reflected by mortality statistics in the form of death certifications for liver disease. In the United Kingdom mortality from cirrhosis and other liver diseases increased slowly from the 1970 s to the early $1990 \mathrm{~s}^{1}{ }^{1}$ We aimed to ascertain the current mortality from liver disease in the West Midlands region of the United Kingdom.

\section{Methods and results}

The study was set in three adjacent metropolitan boroughs in the West Midlands with a total population of 837000 . Around $8.4 \%$ of residents are of south Asian origin (Indian, Pakistani, or Bangladeshi; 1991 census). Deaths from liver disease were identified from public health mortality files supplied by the Office for National Statistics, which we searched using ICD-9 (international classification of diseases, 9th revision) reference codes 570-573, and from files supplied by the registrar of the local health authority. South Asian origin and religion were identified from subjects' names. In cases of deaths from liver disease of unspecified cause (ICD 571.5 and related codes) we analysed case notes to search for underlying causative factors.

Crude mortality from primary liver disease increased from 6.0 per 100000 population in 1993 to $12.7 / 100000$ in 2000 (figure). The increase was almost exclusively the result of alcoholic liver disease (ICD codes 571.0-571.3), which increased almost threefold from $2.8 / 100000$ in 1993 to $8.0 / 100000$ in 2000 (regression coefficient $+0.89 / 100000 /$ year, $95 \%$ confidence interval 0.57 to 1.21 ), although it seemed to have stabilised from 1998 onwards. Rates of increase in deaths from alcoholic liver disease were similar for white men, white women, and Asian men. Asian men 


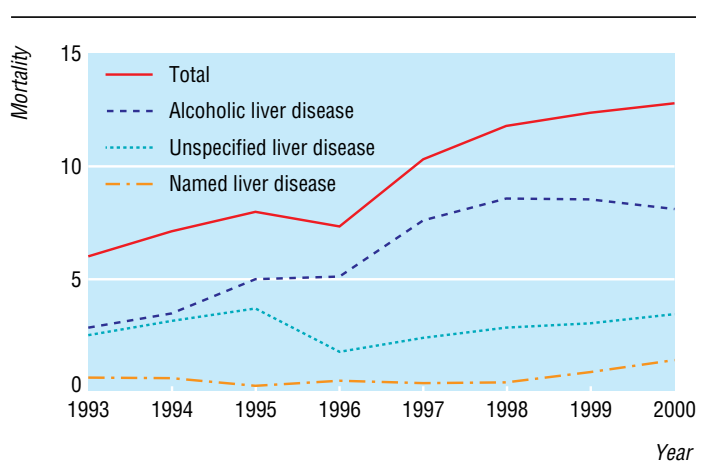

Crude mortality from primary liver disease in the West Midlands per 100000 population, $1993-2000$

had a standardised mortality ratio 3.79 times (3.21 to 4.26) that of white men (based on 46 observed deaths compared with 12.4 expected by extrapolation from the white male population). ${ }^{2}$ Eighty per cent of the Asian men were judged to be of Sikh religion.

After alcoholic liver disease, the largest cause of death was "unspecified" liver disease, with an annual incidence of 2.5/100 000 population (figure). Alcohol misuse was the presumed cause in $67 \%$ (44) of 66 such cases as judged by analysis of case notes. Annual mortality from other defined liver diseases was about $0.5 / 100000$.

\section{Comment}

Deaths from alcoholic liver disease increased in the West Midlands in the past decade; this is also a nationwide trend. ${ }^{3}$ The increasing prevalence of alcoholic liver disease is corroborated by our own data and data on increasing admission rates for patients with alcoholic liver disease to hospital. ${ }^{4}$

This apparent increase might be the result of increasing alcohol consumption, but available evidence does not show any notable increase in the total national alcohol consumption in the past decade nor in the number of people drinking heavily. ${ }^{5}$ The type of alcoholic drink consumed and dietary or other (such as genetic or unidentified environmental) factors may therefore be implicated. The increasing prevalence of alcoholic liver disease among Asians may also be contributing; although the overall population of Asians in our study is small, their excess risk of mortality is worth further study. Our study cannot disprove the possibility of an artefactual increase in morbidity and mortality from alcoholic liver disease as a result of clinicians changing their certification practice, although we are unaware of any evidence to support such a change in certification in the past decade.

These data have important implications for public health and hospital physicians. The halting or reversal of the trend in deaths from alcoholic liver disease that we have described requires further public emphasis on the risk of fatal liver disease from excessive alcohol consumption.

We thank Tim Marshall, Department of Public Health and Epidemiology, University of Birmingham, for informal statistical advice and Amtar Ali and Amrik Jheeta for help with assigning Asian religions.

Contributors: NCF conceived and coordinated the study, and wrote the manuscript. JH and JNR computed the standardised mortality ratio details. JH, AP, JNR, and ETS each provided practical help and critical input into the study methodology, and each critically reviewed the final manuscript. G Criddle (Dudley Health Authority), J Gwinnett (Wolverhampton Health Authority), and C Matthews (University of Wolverhampton, Division of Clinical Sciences) extracted and tabulated data for the study.

Funding: Wolverhampton Digestive Foundation.

Competing interests: None declared.

1 Noble B. Deaths associated with the use of alcohol, drugs, and volatile substances. Population Trends 1994;76:1-11.

2 Armitage P, Berry G. Statistical methods in medical research. 3rd ed. London: Blackwell, 1994.

3 Medical Council on Alcohol. June 2001. www.medicouncilalcol.demon.co.uk (accessed 7 May 2002).

4 Chick J. Evidence suggesting increasing health damage in Scotland related to alcohol. Health Bull 1997;55:134-9.

5 Department of Health. Statistics on alcohol: 1976 onwards. London: Stationery Office, 1999. (Health Bulletin 1999/24.)

(Accepted 25 January 2002)
Wolverhampton Health Authority, Wolverhampton WV13 0XE A Phillips director of public health

Sandwell Health Authority, West Bromwich B70 9LD J N Rao consultant in public health medicine

University of

Wolverhampton, Division of Clinical Sciences, New Cross Hospital,

Wolverhampton WV10 0QP

E T Swarbrick consultant physician and gastroenterologist

Correspondence to: N Fisher

Neil.Fisher@dudleygohtr.wmids.nhs.uk

\section{One hundred years ago \\ The medical aspects of the Royal Academy}

In former years we have felt it our duty, as guide, philosopher and friend of the medical profession, to run our eye over the walls of the Royal Academy, and see which pictures, if any, had any bearing on our craft. This year, however, has been a sad disappointment, for only two of the 795 canvases that have passed the scrutiny of the Hanging Committee have any direct bearing on the subjects with which we are most familiar. The first of these, 190, is "The Borgia" by Orchardson, and it tells a terrible tale with grim dramatic force and admirable technical skill. There has been a little dinner of four, in the open air, under some funereal trees, and a sky from which the brightness of day is only just beginning to fade. Two of the guests have gone, the third perforce remains, and the host sits watching him with a subtle and most impressive blend of triumph and satisfied ambition, tinged perhaps with just a shadow of regret. The victim has fallen forward on the table, one hand convulsively grasps the cloth, his face is hidden, some convulsive movement has flung over his glass, and he is either dead, or rapidly nearing the end. Speculation naturally turns the mind to consider what kind of poison has been employed in this case. The popular belief is that the Borgias had the guilty knowledge of various lethal drugs, mostly vegetable and tasteless, which were generally dissolved in wine, and whose presence in the body defied the rude methods of analysis known in those days. Some of them may be supposed to have so far imitated natural physiological processes, or those of disease, as to give rise to no suspicion which could be safely translated into practical action against such a powerful ruling family. In this case the poor young man-for such he seems to be-looks as though he had simply fallen asleep after a carouse, and in due time he will be removed to the grave of his forefathers, away from the intrigues and dangers and temptations of mediaeval Italy. No. 295 introduces us to "The Plague," under the auspices of the Hon. John Collier, who has painted with ghastly realism the figure of a smart lady of the Middle Ages smitten by the swift thunderbolt of that terrible disease, and lying in all her finery with her pale face turned up to the sky, while her terror-stricken companion makes hastily for the door.

(BMJ 1902;i:1168) 